\title{
Persistent organochlorine pesticides and polychlorinated biphenyls in air of the North Sea region and air-sea exchange
}

\author{
Carolin Mai $^{1}$ • Norbert Theobald ${ }^{1} \cdot$ Heinrich Hühnerfuss ${ }^{2} \cdot$ Gerhard Lammel $^{3,4}{ }^{\text {(B) }}$
}

Received: 26 November 2015 / Accepted: 26 August 2016/Published online: 12 September 2016

(C) The Author(s) 2016. This article is published with open access at Springerlink.com

\begin{abstract}
Organochlorine pesticides (OCPs) and polychlorinated biphenyls (PCBs) were studied to determine occurrence, levels and spatial distribution in the marine atmosphere and surface seawater during cruises in the German Bight and the wider North Sea in spring and summer 20092010. In general, the concentrations found in air are similar to, or below, the levels at coastal or near-coastal sites in Europe. Hexachlorobenzene and $\alpha$-hexachlorocyclohexane $(\alpha-\mathrm{HCH})$ were close to phase equilibrium, whereas net atmospheric deposition was observed for $\gamma-\mathrm{HCH}$. The results suggest that declining trends of $\mathrm{HCH}$ in seawater have been continuing for $\gamma-\mathrm{HCH}$ but have somewhat levelled off for $\alpha-\mathrm{HCH}$. Dieldrin displayed a close to phase equilibrium in nearly all the sampling sites, except in the central southwestern part of the North Sea. Here atmospheric deposition dominates the airsea exchange. This region, close to the English coast, showed remarkably increased surface seawater concentrations. This observation depended neither on riverine input nor on the
\end{abstract}

Responsible editor: Philippe Garrigues

Electronic supplementary material The online version of this article (doi:10.1007/s11356-016-7530-3) contains supplementary material, which is available to authorized users.

Gerhard Lammel

g.lammel@mpic.de

1 Federal Maritime and Hydrographic Agency (BSH), Bernhard-Nocht-Str. 78, 20359 Hamburg, Germany

2 Department of Chemistry, University of Hamburg, Martin-Luther-King-Platz 6, 20146 Hamburg, Germany

3 Multiphase Chemistry Department, Max Planck Institute for Chemistry, Hahn-Meitner-Weg 1, 55128 Mainz, Germany

4 Research Centre for Toxic Compounds in the Environment, Masaryk University, Kamenice 5, 62500 Brno, Czech Republic elevated abundances of dieldrin in the air masses of central England. A net depositional flux of $p, p^{\prime}$-DDE into the North Sea was indicated by both its abundance in the marine atmosphere and the changes in metabolite pattern observed in the surface water from the coast towards the open sea. The longterm trends show that the atmospheric concentrations of DDT and its metabolites are not declining. Riverine input is a major source of PCBs in the German Bight and the wider North Sea. Atmospheric deposition of the lower molecular weight PCBs (PCB28 and PCB52) was indicated as a major source for surface seawater pollution.

Keywords Air-sea exchange $\cdot$ North Sea $\cdot$ Organochlorine pesticides $\cdot$ Polychlorinated biphenyls

\section{Introduction}

Anthropogenic chemicals, which are persistent and thus resist degradation in the environment, pose a long-term hazard for ecosystems on a large spatial scale (i.e. far beyond the area of initial release). For semi-volatile substances (i.e. those with a vapour pressure over the subcooled liquid in the range $10^{-6}$ $10^{-2} \mathrm{~Pa}$ at $20^{\circ} \mathrm{C}$ ), the long-range atmospheric transport is enhanced by the multi-hopping potential (subsequent cycles of atmospheric transport, deposition and re-volatilisation from land or sea surfaces; grasshopper effect; Gouin et al. 2004; Semeena and Lammel 2005) and their spatial range is often even global (Wania and Mackay 1993; Leip and Lammel 2004). For this reason, a number of persistent organic pollutants (POPs) are restricted under internationally binding regulations, i.e. the global Stockholm Convention on Persistent Organic Pollutants (UNEP 2010) and the POPs protocol to the regional Convention on Long-range Transboundary Air Pollution (UNECE 1998). 
The exposure of the marine environment to POPs, both of the global ocean (e.g. Atlas and Giam 1981; Iwata et al. 1993) and of the regional seas (Lipiatou and Saliot 1991; Axelman et al. 1995), has been reported for more than two decades. However, to date, there is still no long-term monitoring established (Lohmann and Muir 2010). Instead, the assessment has to rely on ship cruises and measurements at coastal sites. The North Sea had been found to receive large amounts of organochlorine pesticides (OCPs) and polychlorinated biphenyls (PCBs), but in recent decades, decaying trends in seawater (due to decreasing primary and secondary emissions) have been observed (Brockmann et al. 1994; BSH 2009, 2013). Besides riverine input, dry and wet atmospheric depositions are also input pathways for the pollution of seawater by POPs (Ilyina et al. 2008; O’Driscoll et al. 2013). POP cycling in shelf seas includes transport by winds and sea currents, atmospheric deposition and re-volatilisation from surface seawater, sinking and re-suspension with suspended particulate matter (SPM), phase partitioning in air (aerosol particles) and seawater (SPM), alongside other processes. This is connected to the carbon cycle (Bidleman and McConnell 1995; Lohmann et al. 2007; O’Driscoll et al. 2013).

In the North Sea region, POPs have been measured in rainwater (Baart et al. 1995; Hühnerfuss et al. 1997; Bethan et al. 2001) and surface seawater (Faller et al. 1991; BSH 2009, 2013) and also bioaccumulating along the marine food chain (Falandysz et al. 1994; Bruhn et al. 1999; Dittmann et al. 2012). So far, however, unlike in other European seas, few POP measurements have been made in the atmosphere above the North Sea. In the framework of several annual monitoring cruises performed by the Federal Maritime and Hydrographic Agency of Germany (BSH), the riverine input of OCPs and PCBs and their spatial distribution in surface seawater has been well investigated in the last decades (BLMP 2005; BSH 2009, 2013). Complementary to the seawatermonitoring programme, this study investigated the spatial and seasonal distribution of OCPs and PCBs in the marine atmosphere in 2009 and 2010 in order to assess their cycling in the North Sea region, to verify long-term trends and to advance knowledge of the contribution of atmospheric deposition to surface seawater contamination.

\section{Methods}

\section{Air sampling and sample preparation}

In short, high-volume air samplers (Digitel DHM-60, Riemer, Hausen, Germany) were operated on the top deck of research vessels. In order to sample particulate and gaseous fractions of organics in air separately, these were equipped with glass fibre filters (GFFs, MN85/90BF of $15 \mathrm{~cm}$ diameter, MachereyNagel, Düren, Germany) and adsorber cartridges (ORBO
2500, Supelco, Sigma-Aldrich, Taufkirchen, Germany) consisting of a sandwich of polyurethane foam (PUF) and XAD-2. More experimental details are described in Mai (2012) and Theobald et al. (2013).

Seasonal variations of organics in air were investigated by means of PUF disc passive air sampling (PAS; Klánová et al. 2006; Yusà et al. 2009) at a residential land based sampling site (Hamburg-Sülldorf, $\approx 100 \mathrm{~km}$ from the North Sea coast) and at a rural coastal sampling site (Tinnum/Sylt) between October 2009 and December 2010. The PUF discs were simultaneously exchanged in fixed time intervals of 28 days. Sampling rates were controlled by the recoveries of performance reference compounds (PRCs) spiked prior to exposure (Water sampling and sample preparation) and are reported in ng/sample.

PUF plugs, PUF discs and XAD-2 were rinsed with tap water and underwent Soxhlet extraction with acetone, hexane and methanol for $12 \mathrm{~h}$ each. The pre-cleaned adsorbent materials were dried in a vacuum desiccator for periods ranging from 24 to $48 \mathrm{~h}$. Thereafter, they were stored in a freezer $\left(-20{ }^{\circ} \mathrm{C}\right)$ until use. GFFs were baked at $500{ }^{\circ} \mathrm{C}$ in a muffle furnace for $24 \mathrm{~h}$, placed in pre-cleaned petri dishes and stored in a freezer at $-20^{\circ} \mathrm{C}$.

Prior to exposure, all sampling media were defrosted. Afterwards, the adsorber cartridges and PUF discs (including field blanks) were spiked with PRCs. Field blanks were handled and stored like the samples.

All air samples were defrosted prior to extraction, spiked with internal standards and successively extracted by two azeotropic solvent mixtures, namely acetone/hexane (60/40 $v / v)$ and acetone/methanol $(90 / 10 \mathrm{v} / v)$. The extracts were unified and aliquoted. One aliquot was concentrated and solvent exchanged to hexane for GC-MS/MS analysis. The other aliquot was used for additional investigations (Theobald et al. 2013). More experimental details are presented in the supporting material (SM), S1.2 and S1.3, as well as in Mai (2012) and Theobald et al. (2013).

\section{Water sampling and sample preparation}

One hundred litres of unfiltered water was taken by a glass bowl at fixed stations from $5 \mathrm{~m}$ depth.

Water samples were extracted with $1 \mathrm{~L}$ of pentane immediately after sampling; the extraction was done directly in the sampling glass bowl. Before extraction, a solution of deuterated internal standards was added to the water sample. The dried extract $\left(\mathrm{Na}_{2} \mathrm{SO}_{4}\right)$ was concentrated to ca. $0.1 \mathrm{~mL}$ and pre-cleaned on a small $\mathrm{SiO}_{2}$ column. The extract $\left(\mathrm{CH}_{2} \mathrm{Cl}_{2} / \mathrm{MeOH} 20 / 80\right)$ was concentrated and analysed by GC-MS/MS as described for the air samples (SM, S3). The method had been described in more details earlier (Theobald et al. 1995, 2013). 


\section{Quality assurance and quality control}

The reproducibility of air sampling data was controlled by simultaneous side-by-side exposures of two PUF disc passive air samplers and two high-volume active air samplers, respectively, at Hamburg-Sülldorf. The calculated maximum error of air sampling data varied between 9 and $27 \%$ depending on the sampling medium, analyte and the type of instrumental analysis. In addition, desorption experiments were carried out by spiking PRCs to the adsorber cartridge prior to sampling. Sampling errors caused by desorption were assessed to be less than $15 \%$ for the average sample volume of $260 \mathrm{~m}^{3}$. The stability of the exposed air sampling material during storage in the freezer was controlled and verified by the recoveries of PRCs in field blanks, which were stored for identical time periods as the air samples. Quality assurance of sample preparation was performed by field blanks, laboratory blanks and spike experiments for each air sample preparation sequence. Field blanks were generated at least in triplicate and were used as control for possible contamination sources of air samples during handling in the field, transport, and handling and analysis in the laboratory. Hence, field blanks provided the data (SM, S1.4) for the blank correction of air sample concentrations as well as for the calculation of the limits of quantification/detection (LOQs/LODs). In addition, laboratory blanks were obtained for different critical stages in air sample preparation, namely extraction, evaporation and cleanup. Significant concentrations of the target compounds in laboratory blanks were not observed. Spike control samples were generated for the whole sample preparation procedure (SM, S1.5) as well as for different stages of sample preparation in accordance with the blank data. LOQs were derived from the signal to noise ratio and the field blanks of each target analyte (SM, S1.6).The analytical determinations of the water samples were done within the regular monitoring programme of the Federal Maritime and Hydrographic Agency (BSH), Hamburg, Germany (BLMP 2005; BSH 2013). The BSH and the procedures are accredited by EN/ISO 17025. External quality assurance was proven by regular participation in laboratory performance studies of Quality Assurance of Information for Marine Environmental Monitoring in Europe (QUASIMEME). Generally, more than $90 \%$ of the data had a $Z$-score of $<2$ and were thus considered acceptable. Specific validation and quality assurance parameters are presented in the SM, sections S1.3-S1.6. Sampling was field blank controlled (SM, section S1.4). Recoveries of spike control samples were mostly between 80 and $110 \%$ (SM, section S1.5). Reproducibilities for the whole method based on replicates were between 5 and $20 \%$.

\section{Air mass history}

Recent air mass history was investigated by the calculation of backward trajectories, $24 \mathrm{~h}$ in time and 7 days in time, as well as arrival heights 200, 500 and $1000 \mathrm{~m}$. The Hybrid SingleParticle Lagrangian Integrated Trajectory (HYSPLIT) model was used (version 4.9, NCEP Global Data Assimilation System meteorological data; Draxler and Rolph 2003). The trajectories do not reflect dispersion and entrainment of air parcels along transport but merely the central path, being more indicative the closer in time and the more stable the flow.

\section{Fugacities}

The direction of the net flux of the diffusive gas exchange of a given compound was derived from the ratio of the fugacities in the water and air phases, fugacity ratio $(\mathrm{FR})=f_{\mathrm{w}} / f_{\mathrm{a}}$ (Paterson et al. 1991; Bidleman and Connell 1995). The method is explained in the SM, S1.7.

\section{Results and discussion}

\section{Chlorinated benzenes}

Hexachlorobenzene (HCB) was identified in all air samples, by average $58 \mathrm{pg} / \mathrm{m}^{3}$. The particulate mass fraction of this compound was $\theta=0.00$ (sample volume weighted average). HCB was found to be homogeneously distributed (Figs. Fig. 1 and Fig. 2; Table S6) without significant dependence on the sampling sites or the air mass backward trajectories (SM, Figs. S1-S2). Seasonal fluctuations in its atmospheric concentrations were not observed; monthly passive air sampling data at Hamburg-Sülldorf were $9.2 \pm 1.2 \mathrm{ng} / \mathrm{sample}$ (mean \pm standard deviation, data not shown). A similar distribution pattern was documented in surface seawater (Figs. Fig. 1 and Fig. 2; Table S7). HCB was found throughout all water sampling sites in the German Bight, as well as the wider North Sea, with a the concentration of $2-5 \mathrm{pg} / \mathrm{L}$ beyond river plumes. In addition, the concentration gradient in the German Bight emerging from the riverine input of the Elbe was found smaller than for other pollutants. Maximum concentrations of 6-13 pg/L were quantified in the river plume of the Elbe. The small concentration gradients of HCB within the German Bight (and its homogeneous distribution in the surface water of the wider North Sea) pointed to a predominant atmospheric deposition of HCB and to the riverine input having little importance.

The HCB concentrations found in air are both comparable to other sites in the marine environments of Europe (Table 1) as well as to the European median background, 
a
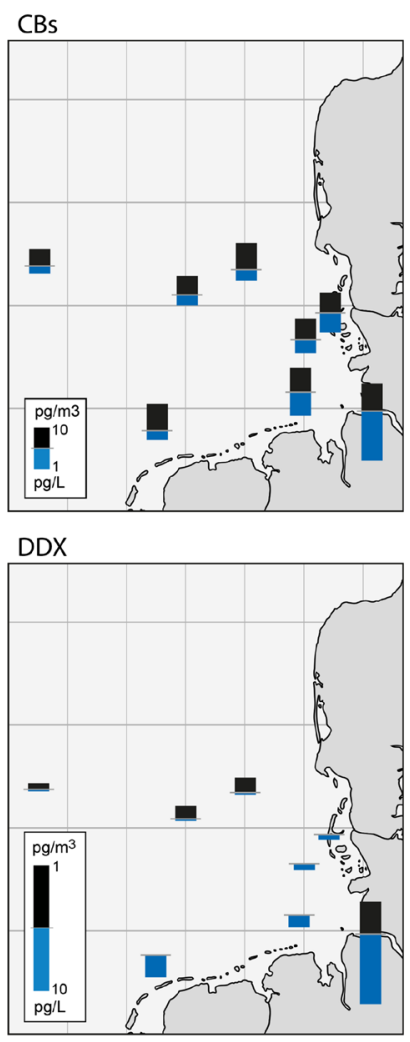

b

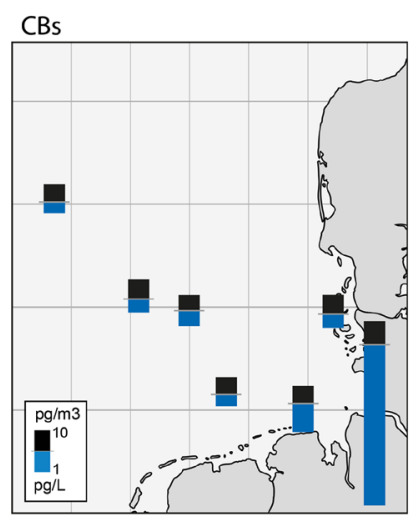

DDX

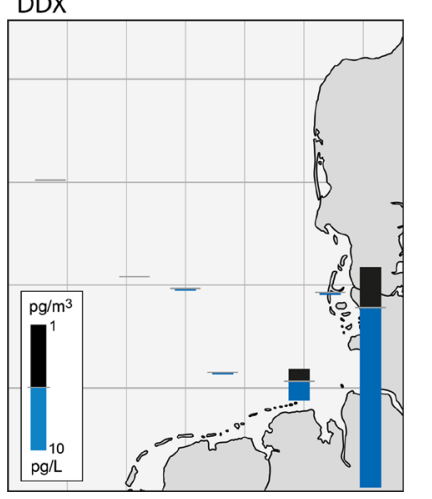

Fig. 1 Air and seawater concentrations determined in the German Bight in a May/June 2009 and b May 2010. Values in the $\mathrm{HCH}$ concentration distribution denote the isomer ratio $\alpha-\mathrm{HCH} / \gamma-\mathrm{HCH}$ in air and surface water, respectively which was determined to be $45 \mathrm{pg} / \mathrm{m}^{3}$ in the summer of 2006 (Halse et al. 2012).

The calculation of the net-flux direction of diffusive gas exchange indicated a close to phase equilibrium of HCB within the river plume of the Elbe $\left(\mathrm{FR}=f_{\mathrm{w}} / f_{\mathrm{a}}=1.0-1.6\right)$, with a tendency towards net deposition for the western areas of the German Bight $(F R=0.4-0.5)$ and the wider North Sea $(\mathrm{FR}=0.4-0.7)$. We used the Tinnum/Sylt data set to investigate whether the concentration in air was controlled by local relaxation to the air-water phase equilibrium. In such a case, the temperature dependence of concentration in the gaseous phase (vapour pressure) would follow the Clausius-Clapeyron equation ( $\ln \mathrm{p}=-\Delta H_{\mathrm{exp}} / \mathrm{RT}+b$; Hoff et al. 1998; detailed in $\mathrm{SM}, \mathrm{S} 2.2)$. This data set is suitable as it covers a wide range of ground temperatures and, according to the prevailing wind direction, the site should monitor air subject to air-sea gas exchange. The observed slope of the linear regression was far from the value of enthalpy of volatilisation from the liquid phase (see SM, S2.2), indicating that concentrations were not controlled by volatilisation from sea surface but instead by long-range transport (Hoff et al. 1998).

In summary, the results of this study confirmed earlier findings that $\mathrm{HCB}$, in the atmospheric environment across Europe, is homogeneously distributed (Jaward et al. 2004; Halse et al. 2011; Table 1) and close to phase equilibrium in the marine environment in areas with continental influence (Lohmann et al. 2009; 2012).

No such conclusion can be drawn for pentachlorobenzene (QCB). Although QCB was found in homogeneous concentrations of $13 \mathrm{pg} / \mathrm{m}^{3}$ throughout the marine atmosphere $(\theta=0.00$; Figs. Fig. 1 and Fig. 2; Table S6), concentrations ranging from 1 to $5 \mathrm{pg} / \mathrm{L}$ were found in the surface water of the German Bight and the river delta of the Rhine/Maas/Schelde only (Figs. Fig. 1 and Fig. 2; Table S6). A minor riverine input by the Elbe was indicated by the small concentration gradient within the German Bight.

The calculation of the direction of diffusive gas exchange revealed ambiguous results: Net deposition was indicated for the German Bight in 2009 ( $F R=0.2-0.5)$, whereas close to phase equilibrium was suggested in 2010 ( $\mathrm{FR}=0.8-2.0$ ) throughout all sampling sites. Differences in temperatures between these two episodes (by average $\approx 1 \mathrm{~K}$ colder in 2010 ) would support change in flux direction. However, air-sea exchange of POPs is controlled by the combination of the parameters temperature, wind speed and concentration in surface water (Stemmler and Lammel 2011). Moreover, it has been observed that the direction of air-sea exchange may fluctuate once the substance concentration has approached (or is close to) phase equilibrium on a range of time scales (Jantunen and Bidleman 1995; Stemmler and Lammel 2009; Berrojalbiz et al. 2014; Mulder et al. 2014; Lammel et al. 2016). This could explain these observations. It has been pointed out (Lammel et al. 2016) that longer observations (and those 
Fig. 2 Same as Fig. Fig. 1 but in the wider North Sea in August/ September 2009
CBs

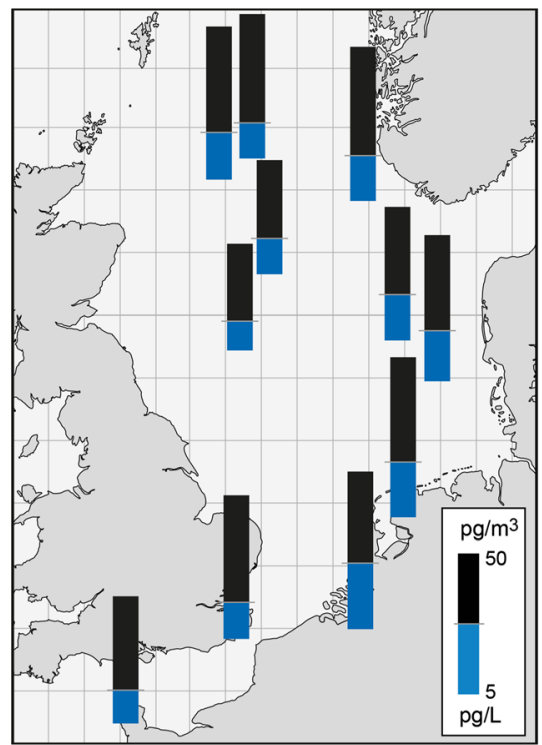

$\mathrm{HCH}$
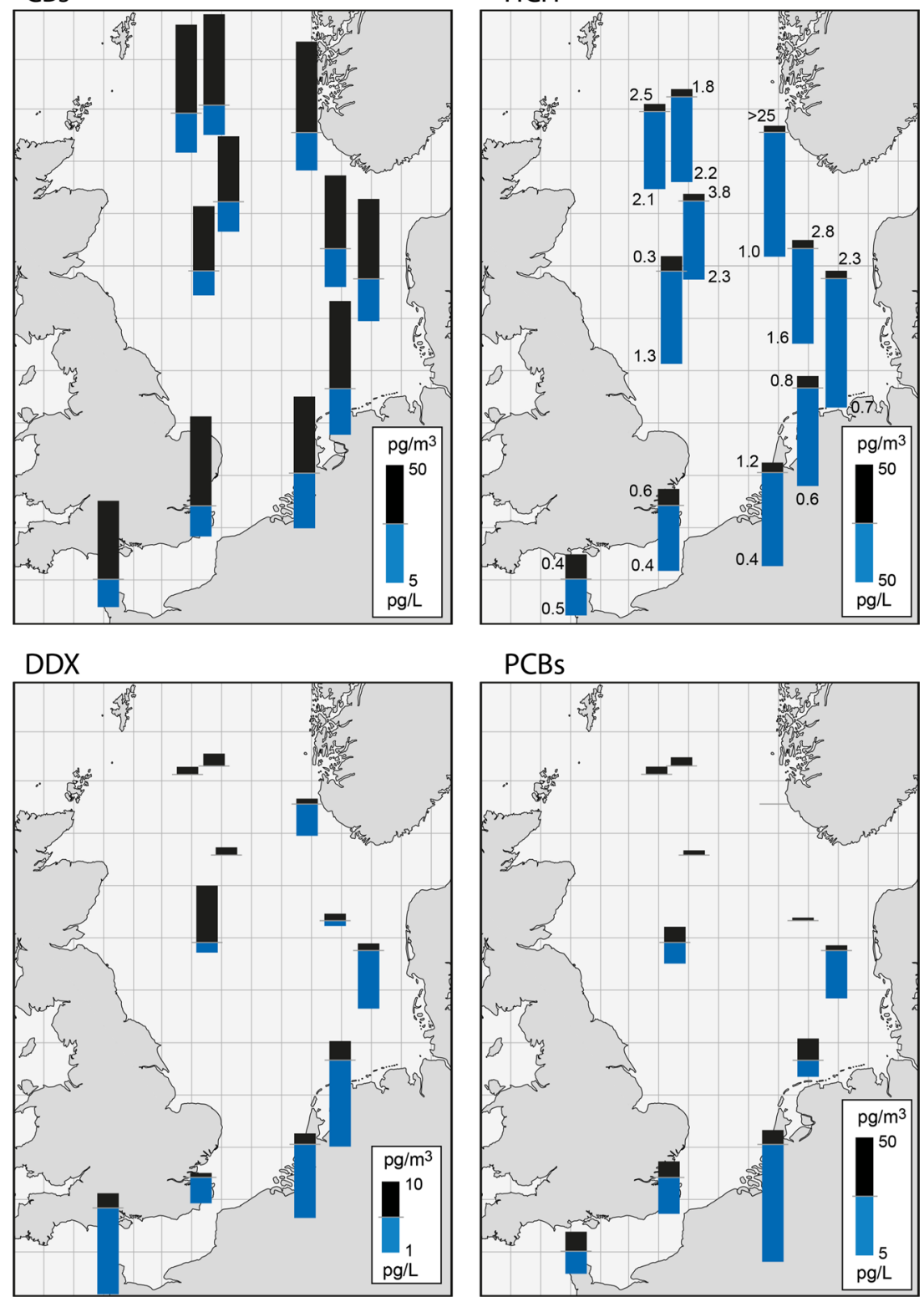

across seasons) of the flux is needed to assess the state of airsea exchange of such substances. Atmospheric deposition of QCB to the wider North Sea could not be documented, because of concentrations below LOQ in most surface water samples. However, net deposition of QCB could not be excluded because of its spatially, almost invariant, abundance in North Sea air.

\section{Hexachlorocyclohexanes}

Hexachlorocyclohexanes were found in the gaseous phase of the atmospheric samples only (particulate mass fraction $\theta<0.02)$. $\beta-\mathrm{HCH}$ was scarcely detected, then mostly $<\mathrm{LOQ}$, whereas $\alpha-\mathrm{HCH}$ and $\gamma-\mathrm{HCH}$ were quantified at most of the sampling sites (Table S6), with $\alpha-\mathrm{HCH} / \gamma-$
$\mathrm{HCH}=1.4 \pm 0.8$ (mean \pm standard deviation, data shown in Figs. Fig. 1 and Fig. 2).

$\alpha-\mathrm{HCH}$ was homogeneously distributed in the marine atmosphere exhibiting concentrations of $4.90 \pm 1.78 \mathrm{pg} / \mathrm{m}^{3}$. Its spatial distribution was found to be unaffected by season and the air mass history (Figs. Fig. 1 and Fig. 2; Table S6), including even air mass histories in the North Atlantic (Fig. Fig. 2; Table S6b: PE15, PE16; air mass history of the last 7 days in Fig. S2). This is in agreement with model results which showed that $\alpha-\mathrm{HCH}$ is more homogeneously distributed in the seawater of the North Sea. This is in contrast with the $\gamma$ $\mathrm{HCH}$ distribution (Ilyina et al. 2008). This might be related to the outgassing of $\alpha-\mathrm{HCH}$ from the North Atlantic and ice-free regions of the Arctic Ocean reported in previous studies (Bidleman et al. 1995; Bottenheim et al. 2004). Deviations 


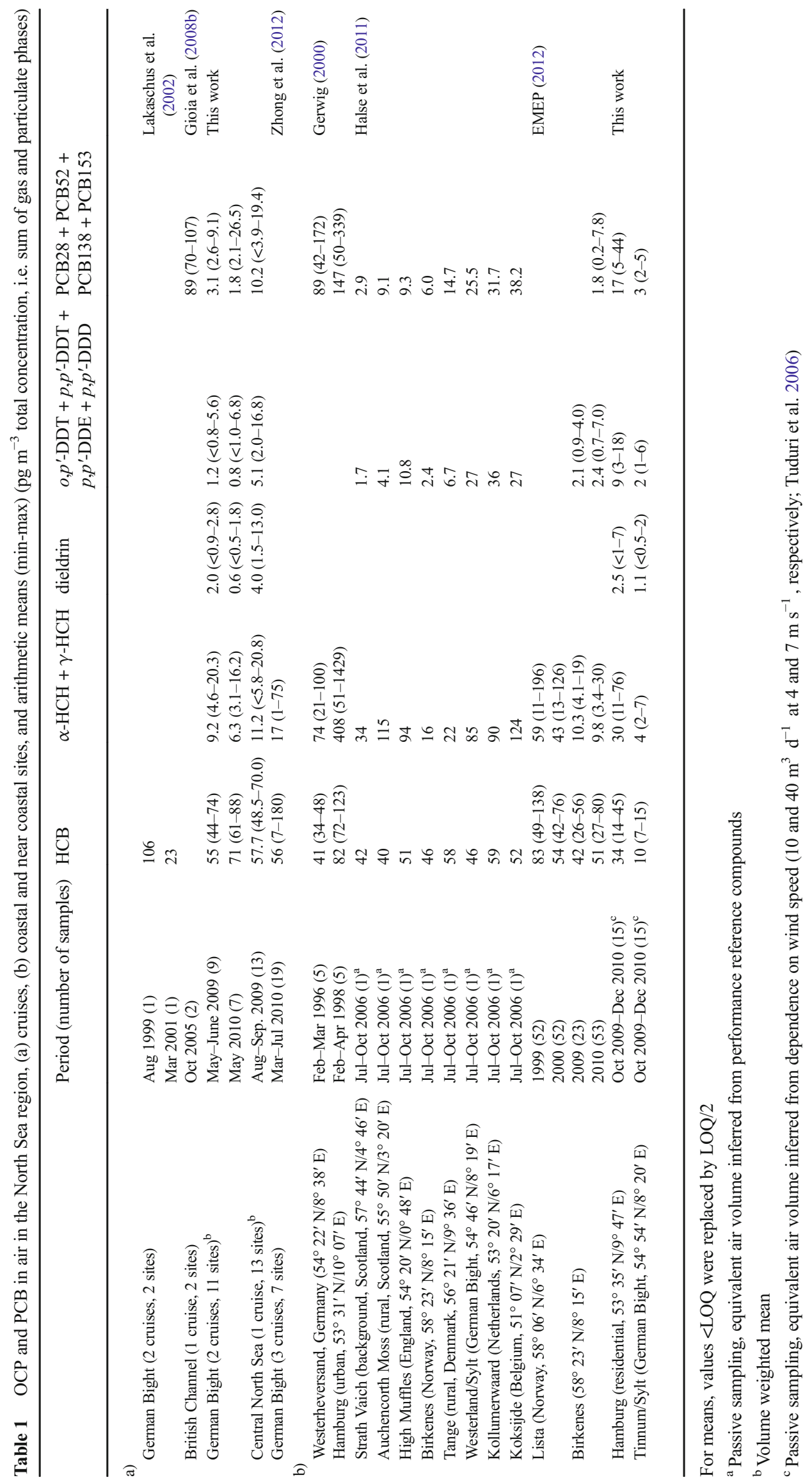


from a fairly constant background level observed over the North Sea were exclusively detected above the river Elbe (Fig. Fig. 1; Table S6: 09AT2, 10AT1), where the concentrations of $\alpha-\mathrm{HCH}$ were higher by a factor of $2-3$. This could be attributed to the proximity of this sampling site to land, where stronger secondary emission sources (e.g. revolatilisation from contaminated soil) could be expected. By contrast, the concentrations of $\gamma-\mathrm{HCH}$ in the marine atmosphere varied in the range $1-16 \mathrm{pg} / \mathrm{m}^{3}$. In addition, a strong dependency of the $\gamma$-HCH abundances on the air mass history could be documented (Figs. Fig. 1 and Fig. 2, Table S6): Highest concentrations were quantified in air masses which recently $(<24 \mathrm{~h}$ back) had passed over England (Fig. Fig. 2; Table S6: PE7, PE10) or France (PE4, PE6). However, a definite source region was not indicated. This was anticipated considering the pronounced multi-hopping potential of this substance (Semeena and Lammel 2005) and recent analysis of its secondary sources in Europe (Dvorská et al. 2009). In general, the $\gamma-\mathrm{HCH}$ concentration increased the longer the air masses had passed over the continent, while in air without significant continental influence, a concentration of $<4 \mathrm{pg} / \mathrm{m}^{3}$ was determined. This is expected as elevated levels prevail over land of central and western European countries, like Germany and the UK (Table 1). The strong influence of re-volatilisation of $\gamma$ $\mathrm{HCH}$ from contaminated soils is suggested by the seasonal profile, which shows a strong correlation with ground temperature at Tinnum/Sylt $\left(r^{2}=0.86\right)$ and Hamburg-Sülldorf $\left(r^{2}=0.91\right)$ (Fig. Fig. 3a). Similar observations were made at
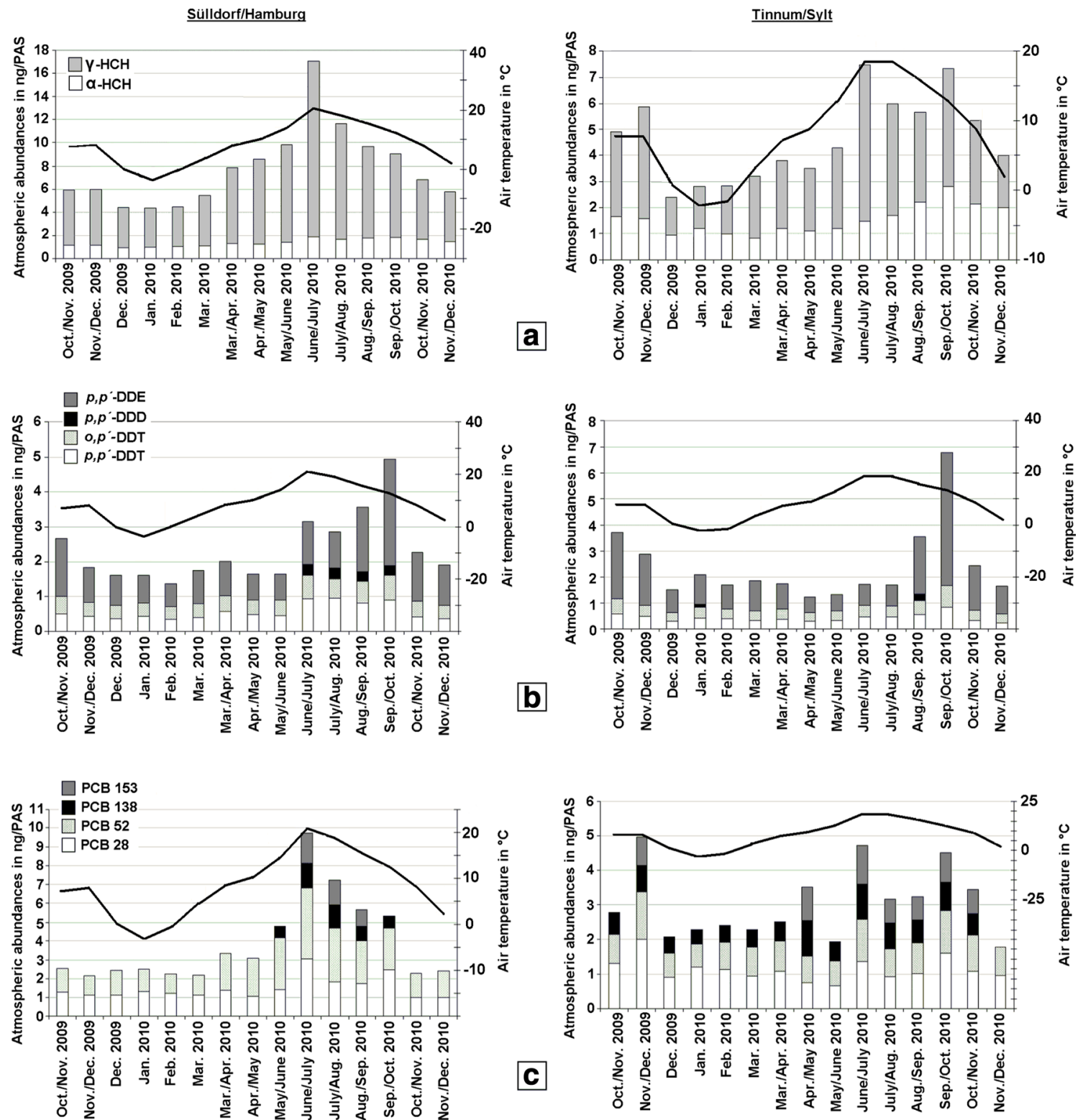

Fig. 3 Seasonal variations of $\alpha-\mathrm{HCH}$ and $\gamma-\mathrm{HCH}(\mathbf{a})$, DDT isomers and metabolites (b) and PCBs (c) together with ambient air temperature at Sülldorf/ Hamburg (left) and Tinnum/Sylt (right) 
a central European background station (e.g. Holoubek et al. 2007). In contrast, no significant seasonal variation of $\alpha-\mathrm{HCH}$ abundances was observed (maximum amplitudes of 1-2 ng/ PAS).

The $\mathrm{HCH}$ concentrations found in this study, particularly in the past, are lower than at most background sites in Europe (Table 1). These are clearly below, namely ca. one fourth of the European median background which was $40.1 \mathrm{pg} / \mathrm{m}^{3}$ in summer 2006 with $\alpha-\mathrm{HCH} / \gamma-\mathrm{HCH} \approx 1.1$ (Halse et al. 2012), i.e. lower than observed here over the open North Sea (Fig. Fig. 2).

Corresponding to their ubiquitous presence in the marine atmosphere, $\alpha-\mathrm{HCH}$ and $\gamma-\mathrm{HCH}$ were also the main isomers in the surface seawater and could be quantified throughout all water-sampling sites of the German Bight and the wider North Sea. In addition, $\beta-\mathrm{HCH}$ was quantified in all surface water samples (Table S7; sites mapped in Fig. S3b). Compared to earlier measurements in the region (BSH 2009, 2013), the declining trends of $\alpha-\mathrm{HCH}$ and $\gamma-\mathrm{HCH}$ with half times of $\approx 4$ years in the period 1989-2005 have been continuing for $\gamma-\mathrm{HCH}$ but somewhat levelled off for $\alpha-\mathrm{HCH}$ (similar concentrations as 2003-2005). Regarding the total of $\mathrm{HCH}$ isomers in surface water, a decreasing concentration with increasing distance along the sea currents to the river estuaries and the outflow of the Baltic Sea was observed (Fig. S3c). Maximum spatial concentration gradients between the Elbe estuary and the wider North Sea of $\approx 3000 \mathrm{pg} / \mathrm{L}$ (Fig. Fig. 1; Table S6 in combination with Fig. S3a) and $\approx 100 \mathrm{pg} / \mathrm{L}$ (Fig. Fig. 2; Table S7c: sampling sites 909 and 911), respectively, were found. Thus, rivers and the outflow of the Baltic Sea were found to be important sources of HCHs to the North Sea. The main $\mathrm{HCH}$ isomers $(\alpha-\mathrm{HCH}$ and $\gamma-\mathrm{HCH})$ displayed inverse spatial trends. Values of $\alpha-\mathrm{HCH} / \gamma-\mathrm{HCH}$ were 0.5 for Atlantic water entering the North Sea by the channel (Fig. Fig. 2). In the southern North Sea, the $\alpha-\mathrm{HCH} / \gamma-\mathrm{HCH}$ ratio is further decreased to 0.4 inside the river plumes of the Thames and the Rhine (Fig. Fig. 2). However, the ratio gradually increased towards the northern North Sea, achieving maximum values of 2.1-2.3 at the northernmost sites sampled (Fig. Fig. 2). Thus, $4-6$ times higher $\alpha-\mathrm{HCH}$ than $\gamma-\mathrm{HCH}$ concentrations were quantified at the remote sampling sites in the northern North Sea (Fig. Fig. 2). These observations were supported by the $\alpha-\mathrm{HCH} / \gamma-\mathrm{HCH}$ ratios found in the German Bight and immediate vicinity: The ratio increased towards the western sampling sites to a maximum of approximately 1.7, while the ratios in the inner German Bight were 0.4 (Fig. Fig. 1). This is quite remarkable as the ratio at the freshwater border of the river Elbe is $\approx 2.4$ (Table S7), which is caused by a specific historic burden, originating in the middle course of the river (ARGE Elbe 2005). Evidently, the water inflow of the Elbe influences a relatively narrow plume region along the North Frisian coast (eastern boundary of the German Bight) only. The observed elevated concentrations of $\gamma-\mathrm{HCH}$ in the southern North Sea can be explained by several superimposed trends. First, $\gamma-\mathrm{HCH}$ is currently used for medical treatments and has been applied as pesticide (lindane) from the 1980 s to the 1990 s, whereas $\alpha-\mathrm{HCH}$ predominantly originates from the usage of technical $\mathrm{HCH}$ in earlier years (Vijgen et al. 2010). Thus, $\gamma$-HCH has been discharged in river plumes and estuaries, historically later than $\alpha-\mathrm{HCH}$. In the German Bight, a clear temporal decline was observed for $\gamma$-HCH only since 1998 , whereas $\alpha-\mathrm{HCH}$ showed downward trends since the mid-1980s (BSH 2009). Secondly, $\alpha-\mathrm{HCH}$ concentration is higher when it originates from primary emission $(55-80 \%$ in technical $\mathrm{HCH}, \alpha-\mathrm{HCH} / \gamma-\mathrm{HCH}=5-7$; IHPA 2006; Vijgen et al. 2010). Although it is similarly resistant to microbial degradation in water (Lammel et al. 2007), it is more resistant to photooxidation (Brubaker and Hites 1998) than $\gamma-\mathrm{HCH}$. Alongside this, a transformation of $\gamma-\mathrm{HCH}$ to $\alpha-$ HCH was observed (Faller et al. 1991). Consequently, the $\alpha$ $\mathrm{HCH}$ abundances can be expected to exceed those of $\gamma-\mathrm{HCH}$ with increasing distance to riverine input. Moreover, atmospheric deposition might also affect the spatial distribution of $\alpha-\mathrm{HCH}$ and $\gamma-\mathrm{HCH}$ in surface seawater, because both were ubiquitously present in the marine atmosphere. A similar spatial trend for the $\alpha-\mathrm{HCH} / \gamma-\mathrm{HCH}$ ratio was found earlier in the region (UK and Norwegian sites; Ockenden et al. 1998). The spatial gradients in Europe seem to be somewhat steeper for $\gamma$ $\mathrm{HCH}$ than for $\alpha-\mathrm{HCH}$ (e.g. Halse et al. 2011), possibly influenced by its shorter history of environmental cycling.

The calculation of the net flux of diffusive gas exchange indicated net deposition of $\gamma-\mathrm{HCH}$ into the German Bight and the wider North Sea in spring and summer 2009-10 $(\mathrm{FR}=0.1-0.9)$, whereas close to phase equilibrium could be determined for the Elbe estuary and its river plume $(F R=0.8$ 1.5). This is in agreement with model results (O'Driscoll et al. 2013). Net atmospheric deposition ( $F R=0.2-0.3$ ) of $\alpha-\mathrm{HCH}$ in summer was exclusively found for the southern part of the North Sea (adjacent and inside the English Channel). Phase equilibrium ( $\mathrm{FR}=0.6-1.5)$ of $\alpha-\mathrm{HCH}$ was determined in the German Bight and the wider North Sea in spring and summer. At Tinnum/Sylt (German Bight), neither the $\alpha-\mathrm{HCH}$ nor $\gamma$ $\mathrm{HCH}$ concentrations in air were controlled by local relaxation to (liquid vapour) phase equilibrium (Clausius-Clapeyron equation), even in spring-summer. The observed slope of the linear regression was far from the values of the enthalpy of volatilisation, $\Delta H_{\text {vap }}=67$ and $74.7 \mathrm{~kJ} \mathrm{~mol}^{-1}$, respectively for $\alpha-\mathrm{HCH}$ and $\gamma-\mathrm{HCH}$, again indicating that concentrations were not controlled by volatilisation from the sea surface (details in SM, S2.2). Therefore, advection/long-range transport must have been the main source of $\mathrm{HCH}$. Both experimental and modelling studies found that $\alpha-\mathrm{HCH}$ and $\gamma-\mathrm{HCH}$ volatilise from the surface seawater of the Elbe estuary in summer (Bethan et al. 2001; Ilyina et al. 2008). Net volatilisation was not found in this study in spring. However, volatilisation could occur in summer (due to higher 
temperatures) while long-range transport may sustain the concentrations observed (in spring).

In summary, a close to phase equilibrium of $\alpha-\mathrm{HCH}$ was observed in the marine environment of the North Sea in spring and summer of 2009 and 2010. This was indicated by the constant atmospheric concentrations unaffected by air mass history, the gradually increasing surface water concentrations towards the northern North Sea and the comparison of air and water fugacities. By contrast, a net dry gaseous deposition was determined for $\gamma-\mathrm{HCH}$ for the same sampling interval. Revolatilisation of $\gamma-\mathrm{HCH}$ from contaminated soil and subsequent transport by advection were observed to be an important source to the marine atmosphere. In addition, riverine input and the Baltic Sea outflow were still major input pathways of $\mathrm{HCHs}$ for surface seawater. The local cycling of $\beta-\mathrm{HCH}$ could not be assessed, because its atmospheric and water concentrations are very low (often $<$ LOQ and LOD).

\section{Cyclodiene pesticides}

The concentrations and spatial distribution of dieldrin in the atmosphere of the German Bight and the wider North Sea could be reported in this study, whereas those for aldrin, endrin and isodrin were $<$ LOD throughout (Table S6). Dieldrin was found exclusively in the gas-phase $(\theta=0.01)$, at concentrations varying between 1.5 and $3.5 \mathrm{pg} / \mathrm{m}^{3}$. Concentrations $<$ LOQ were caused by sample volume limitation. Seasonal variations in atmospheric concentrations were not observed. However, two air samples collected in the wider North Sea (sites PE7 and PE10 in Fig. S2) in August/September 2009 exhibited remarkably increased dieldrin concentrations of 11.4 and $13.0 \mathrm{pg} / \mathrm{m}^{3}$, respectively. The air mass history indicated a common source region in central England.

In correlation to its atmospheric abundances, dieldrin was also widespread distributed in the surface seawater of the German Bight and the wider North Sea, whereas endrin and isodrin were only observed in 3 and 1 water sample, respectively, and aldrin was never detected (Table S7). The surface seawater concentrations of dieldrin varied between 3.1 and $19.6 \mathrm{pg} / \mathrm{L}$. Highest concentrations were quantified inside of the river estuaries and river plumes indicating at least a slight riverine input. However, unusually small concentration gradients (in comparison to other pollutants) from the rivers Elbe and Rhine (Fig. S3d) towards the open sea pointed to a precontamination of background waters. This could be attributed to atmospheric deposition. Further evidence on atmospheric deposition was given by the comparably high dieldrin concentrations of $9-11 \mathrm{pg} / \mathrm{L}$ in the central southwestern part of the North Sea (sampling sites 17, 9, 20). These were obviously unaffected by riverine input considering the sea current profile of the wider North Sea. The remarkably elevated concentrations of dieldrin in the marine boundary layer atmosphere were also observed in this sea region.
The direction of diffusive air-sea gas exchange of dieldrin was net depositional ( $F R=0.1-0.2)$ in the central southwestern part of the North Sea and close to equilibrium adjacent to the exchange regions with the Atlantic Ocean (English Channel/northern North Sea: FR $=0.4$ ) and other parts, consistent with the almost homogenous atmospheric concentrations in spring/summer 2009 and 2010.

\section{DDT isomers and metabolites}

$o, p^{\prime}$-DDT, $p, p^{\prime}$-DDT and the metabolite $p, p^{\prime}$-DDE were quantified mostly in the gas phase of the air over the German Bight and the wider North Sea $(\theta=0.00,0.03$ and 0.03 , respectively; Figs. Fig. 1 and Fig. 2; Table S6), whereas the concentrations of the metabolite $p, p^{\prime}$-DDD were always $<$ LOQ. The metabolite $p, p^{\prime}$-DDE and the parent compound $p, p^{\prime}$-DDT were found to be the main components, ranging $0.7-13$ and 0.4 $3.6 \mathrm{pg} / \mathrm{m}^{3}$, respectively. These values are the first determined in the North Sea and are comparable to others found in the marine environment in the region (Table 1). The DDX concentrations were found to be on average 1.1 and $5.0 \mathrm{pg} / \mathrm{m}^{3}$ over the German Bight and the North Sea, respectively. These are similar to the European median background which was $3.8 \mathrm{pg} / \mathrm{m}^{3}$ in summer 2006 (Halse et al. 2012) and to the findings in the open Mediterranean (2.6 and 2.7-5.2 $\mathrm{pg} / \mathrm{m}^{3}$ in the summers 2010 and 2012; Mulder et al. 2015; Lammel et al. 2015).

Whenever observed, the $o, p^{\prime}$-isomer was quantified in almost the same concentration as $p, p^{\prime}$-DDT. Such an isomer ratio is uncommon in Europe: $p, p^{\prime}$-DDT/o, $p^{\prime}$-DDT $\approx 3.6$ was found as a long-term mean at a central European background site, Košetice (Holoubek et al. 2007). $p, p^{\prime}$-DDT/o, $p^{\prime}$-DDT $\approx 2$ and $\approx 6$ were found in the marine boundary layer of the Mediterranean (Mulder et al. 2015) and in free tropospheric air sampled in the Alps (Lammel et al. 2009), respectively. Such values are closer to the isomer ratio upon primary emission as a pesticide $\left(p, p^{\prime}\right.$-DDT/o, $p^{\prime}$-DDT $\left.\approx 5\right)$, while the ratio in DDT released to the environment as an impurity of another pesticide, dicofol, is often lower. In China, this is as low as $p, p$ '-DDT/o,p'-DDT $\approx 0.15$ (Qiu et al. 2005). However, dicofol marketed in Europe is reportedly low (12 t in Spain in the year 2000, smaller amounts in Portugal, France and the UK; Denier van der Gon et al. 2007), and the DDT impurity in dicofol marketed in Europe is $<0.1 \%$. (Qiu et al. 2005).

Although detected, the DDT isomers and metabolites could be only sporadically quantified in the atmosphere of the German Bight in spring 2009 and 2010. Their atmospheric concentrations were mostly below the LOQ. By contrast, $p, p$ '-DDT was quantified in each air sample collected in the wider North Sea in summer 2009, whereas $p, p^{\prime}$-DDE was determined in 12 out of 13 air samples. A significant relation to the air mass history was found for two air samples collected in the North Sea atmosphere in summer 2009: the $o, p^{\prime}-$ DDT 
isomers were slightly elevated and $p, p^{\prime}$-DDE reached 12.5 and $13.1 \mathrm{pg} \mathrm{m}^{-3}$ (<LOQ $-2.5 \mathrm{pg} \mathrm{m}^{-3}$ at other sites in the North Sea; see Table S6b) in air masses which had previously passed over central England (Fig. S2: sites PE7, PE10).

A small seasonal increase in the atmospheric abundances of $p, p^{\prime}$-DDE was monitored from September to October at land based sampling sites. $p, p^{\prime}$-DDD was observed during a few months (Fig. Fig. 3b), but no such seasonality was found for the DDT isomers. Local sources can be excluded as no correlation with local ambient temperature was observed, and this seasonality was more pronounced at the coastal site Tinnum/Sylt than at the residential site Hamburg-Sülldorf. The cause for this $p, p^{\prime}$-DDE seasonality is unknown. Possible influences are long-range transport (very distant sources) and the sensitivity of the PAS sampling efficiency to wind velocity (Melymuk et al. 2011; Tuduri et al. 2006). The latter is unlikely, as no increased wind speed was recorded at the site during September-October.

The concentrations and spatial distribution of $p, p^{\prime}$-DDT $\left(o, p^{\prime}\right.$-DDT was not targeted in surface seawater analysis) and its metabolites were highly variable within the surface seawater of the German Bight, considering the concentrations observed at individual sampling sites of a single research cruise as well as the fluctuations between the research cruises of two successive years (Figs. Fig. 1 and Fig. 2). On average, the sum of the total concentrations (dissolved and SPM bound) of $p, p$ '-DDT, $p, p$ '-DDD and $p, p^{\prime}$-DDE inside the river plume of the Elbe were two times higher in May 2010 than during May/ June 2009 (966 vs. 523 pg/L at site STADE and 270 vs. $113 \mathrm{pg} / \mathrm{L}$ at site MEDEM, Table S7; see Fig. S3a for site location). The spatial distributions in the inner German Bight observed within 2 years displayed differences depending on the SPM content and the salinity (freshwater fraction) of the water samples At the western border of the German Bight, the DDX concentrations are more homogeneous, but very low (close to or below the LOQs). Therefore, steep concentration gradients within the German Bight were observed, ranging $10-50 \mathrm{pg} / \mathrm{L}$ at coastal stations (Table S7: sites EIDER, ELBE1) and $0.3-0.5 \mathrm{pg} / \mathrm{L}$ in the western German Bight/ Central North Sea (sites ENTE3, ENTE1); the steepness of the gradients is mainly determined by the concentrations at the coastal stations. These variations can be attributed to the strong sorption of DDT isomers and metabolites $\left(\log \mathrm{K}_{\mathrm{OW}}=6-7\right)$ to SPM in the water column. Therefore, the particle loads of rivers and re-suspension processes of contaminated sediments, e.g. during storm events and phytoplankton growth, were expected to be important factors influencing these spatial distributions. A trend of increasing surface water concentrations with increasing SPM content was found, although no significant correlation. This could be explained by the heterogeneous SPM distribution (a strong gradient from coastal and estuarine waters) and differences in the chemical composition and thus adsorption characteristics of the SPM. The spatial distribution of $p, p^{\prime}$-DDT, $p, p^{\prime}$-DDD and $p, p^{\prime}$-DDE indicated a major riverine input into the surface seawater of the German Bight and the wider North Sea. Variations in distribution patterns, additionally pointed to an atmospheric input of $p, p^{\prime}$-DDE. In the Elbe plume (Fig. Fig. 1; Table S6 in combination with Fig. S3a), the concentration of $p, p^{\prime}$-DDD was approximately two times higher than the concentration of $p, p^{\prime}$-DDE. A continuous approximation of the water concentrations of both metabolites, decreasing towards west was observed. This may be explained by air-sea gas exchange or sedimentation with SPM of the two contaminants. In May 2010, at the western sampling sites (Fig. Fig. 1; i.e. sites ENTE3, DTEND and ENTE1 in Table S7), exclusively, $p, p^{\prime}$-DDE was quantified in the surface seawater, whereas $p, p^{\prime}$-DDD concentrations were $<\mathrm{LOQ}$. The same was observed in the wider North Sea. Although $p, p$ '-DDD revealed the highest surface water concentrations inside the river plumes and estuaries, only $p, p^{\prime}$-DDE was quantified at the northern sampling sites.

The concentrations of DDT and its metabolites in surface seawater of the German Bight were not significantly lower, but similar to those measured in 2005 (BSH 2009).

The direction of air-sea gas exchange of $p, p^{\prime}$-DDT was depositional, as indicated by concentrations in the surface water $<$ LOQ (i.e. FR $<0.2$ throughout the North Sea, assuming even total dissolution of the contaminant). $p, p^{\prime}$-DDE, on the other hand, was depositional in the central North Sea but close to phase equilibrium in the German Bight (at location PE1, see Fig. S2, assuming a mostly even association of the contaminant with SPM); $p, p^{\prime}$-DDE had also been found depositional in cold waters of the Atlantic Ocean (Lohmann et al. 2009) and in warm coastal waters (Singapore; He and Balasubramanian 2010). In contrast, $p, p^{\prime}$-DDE was found close to phase equilibrium in the Aegean Sea (Lammel et al. 2015) and net volatilisation in coastal waters of China (East China Sea; Lin et al. 2012). Again, fluctuation of direction of air-sea exchange of $p, p^{\prime}$-DDE as influenced by temperature, wind and concentration in surface water can be expected.

\section{PCBs}

Four PCB congeners, PCB28, PCB52, PCB138 and PCB153, were targeted in this study and could be predominantly quantified in the gaseous phase $\theta=0.06,0.00,0.04$ and 0.26 , respectively; Figs. Fig. 1 and Fig. 2; Table S6). PCB28 was the most frequently detected and concentrations reached the highest atmospheric bulk concentrations of up to $9.1 \mathrm{pg} / \mathrm{m}^{3}$. In addition, PCB52 was quantified in most of the air samples and reached in bulk concentrations up to $6.9 \mathrm{pg} / \mathrm{m}^{3}$. By contrast, PCB138 and PCB153, low volatility congeners (vapour pressures of 0.15 and $0.14 \mathrm{mPa}$ at $25^{\circ} \mathrm{C}$, respectively; Paasivirta et al. 1999) were observed in significantly lower abundances, between $<$ LOQ and $2.6 \mathrm{pg} / \mathrm{m}^{3}$ and $<\mathrm{LOQ}$ and $8.2 \mathrm{pg} / \mathrm{m}^{3}$, 
respectively. These values are for the first determined in the North Sea and are much lower than what was observed in the English Channel in 2005 and similar to or lower than found at coastal or near-coastal sites in Europe (Table 1).

The atmospheric PCB concentrations' variation (Figs. Fig. 1 and Fig. 2) was obviously influenced by continental sources. Lower concentrations were observed with increasing distance to coasts and only PCB28 and PCB52 could be quantified in air masses coming from open waters. The variation of the PAS results for PCB at the residential site, Hamburg-Sülldorf (Fig. Fig. 3), was correlated $\left(R^{2}=0.85\right.$, $p<0.01$ ) with air temperature. During the months of higher mean air temperatures $\left(12-21{ }^{\circ} \mathrm{C}\right)$, the atmospheric abundances of PCB28 and PCB52 were significantly increased and even the less volatile congeners PCB138 and PCB153 were quantifiable. At lower temperatures, exclusively, the more volatile congeners PCB28 and PCB52 were quantified in almost constant atmospheric concentrations. The seasonality observed can be explained by the main source, revolatilisation from ground, being enhanced by ground temperature. The same was reported elsewhere in Europe (Halsall et al. 1999; Holoubek et al. 2007; Cabrerizo et al. 2011). By contrast, no significant variation in atmospheric PCB abundances with season could be observed at the coastal sampling site Tinnum/Sylt (Fig. Fig. 3c). The fraction of the higher chlorinated congeners, PCB138 and PCB153, in the mixture was apparently higher at Tinnum/Sylt $(0.37 \pm 0.08)$ than at Hamburg-Sülldorf $(0.25 \pm 0.06)$. This result is likely biased by differences in LOQ at two sites, which are due to differences in PAS' sampling efficiency as a consequence of differences in wind speed: Based on the results of wind tunnel experiments (Tuduri et al. 2006), the difference in wind speeds between the two sites $(6-9 \mathrm{~m} / \mathrm{s}$ at Tinnum/Sylt and 3-5 m/s at HamburgSülldorf) corresponds to sampling efficiencies differing by a factor of 4 . Limited to those months with concentrations at both sites $>$ LOQ no difference in the mixture is found: For these months, May-October, the fraction of the higher chlorinated congeners was $0.38 \pm 0.04$ at Tinnum/Sylt and $0.40 \pm 0.08$ at Hamburg-Sülldorf. The difference between PCB concentrations observed at the various campaigns (Figs. Fig. 1 and Fig. 2; Table S6) is dominated by the seasonality of PCB in air as reflected in the time series measured at Hamburg (Fig. Fig. 3c). Similar observations had been made for a central European background site (Holoubek et al. 2007). PCB levels over the open sea had been reported earlier to be dominated by advection of continental air (e.g. Schreitmüller et al. 1994; Gioia et al. 2008a, b).

The PCB concentrations (total of dissolved and SPM bound) in surface seawater displayed the typical spatial distribution emerging from riverine input and subsequent transport along the prevailing sea currents (Fig. S3c). Highest PCB concentrations (sum of the four congeners) were determined close to the river estuaries of the Elbe $(10-26 \mathrm{pg} / \mathrm{L}$;
Fig. Fig. 1), the Thames (5 pg/L), the Rhine/Maas/Schelde $(13-14 \mathrm{pg} / \mathrm{L})$ and the region of exchange with the Baltic Sea (1-4 pg/L) (Fig. Fig. 2), reflecting the predominant riverine input of PCBs into the surface seawater. The PCBs were observed throughout all water sampling sites in the German Bight, but decreased below LOQ towards the northern North Sea. The spatial distribution of PCBs in the surface seawater was influenced by the SPM concentration in the water column. Highest relative amounts of the higher molecular weight PCBs, $(\mathrm{PCB} 138+\mathrm{PCB} 153) / \Sigma_{4} \mathrm{PCB}$, were found in areas with high SPM abundances (e.g. the outflow of the river Elbe). Accordingly, the high molecular weight congeners' spatial concentration gradients were steeper than those of the lower molecular weight PCBs. For example in May 2009, PCB138 and PCB153 concentrations ranged from $\approx 11 \mathrm{pg} / \mathrm{L}$ at the coastal site EIDER (see Fig. S3a) to $<1 \mathrm{pg} / \mathrm{L}$ at the open sea sites ENTE3 and ENTE1; but for the same stations, the PCB28 concentrations decreased from 2.4 to $0.2 \mathrm{pg} / \mathrm{L}$, respectively. The atmospheric concentrations of PCB28 and PCB52 indicate that their levels in surface seawater of the open North Sea were strongly influenced by atmospheric deposition. The mean concentration found over the North Sea, $10.2 \mathrm{pg} / \mathrm{m}^{3}$, and the ratio $(\mathrm{PCB} 138+\mathrm{PCB} 153) / \Sigma_{4} \mathrm{PCB}=0.28$ were similar to the European median background of the congeners addressed here which were $11.2 \mathrm{pg} / \mathrm{m}^{3}$ and 0.22 in summer 2006, respectively (Halse et al. 2012).

We refrained from deriving the direction of air-sea diffusive gas exchange from fugacities, because it would have been biased by the large non-dissolved (particle bound) PCB mass fraction in seawater (Ilyina et al. 2008; O'Driscoll et al. 2013). No such observations exist for the North Sea. Downward (depositional) or close to equilibrium (within considerable uncertainty) fluxes had been found in the Baltic Sea in 1999 (Bruhn et al. 2003) and in the North Atlantic Ocean in 2005 (Gioia et al. 2008b). For the North Sea, net volatilisation of PCB153 was predicted throughout most of 1996-2005 based on modelling (Ilyina et al. 2008; O'Driscoll et al. 2013).

To sum up, the results of this study showed that riverine input is a major source of PCBs in the German Bight and the wider North Sea. Atmospheric deposition of the lower molecular weight PCBs (PCB28 and PCB52) was indicated as a major source of surface seawater pollution in the wider North Sea.

\section{Conclusions}

We studied organic pollutants in the North Sea atmospheric environment which are mostly fed by primary and secondary emissions (that have been declining in Europe, and worldwide, since a number of years). Very few such measurements (to compare with) have been reported in the past. This is true even when including coastal and near coastal sites (Table 1). 
The long-term trends of atmospheric concentrations of the pollutants $\alpha-\mathrm{HCH}$ and DDT (and its metabolites) in the North Sea environment are indicated to level off rather than continue to decline. Under varying or eventually decreasing atmospheric concentrations, the direction of diffusive air-sea mass exchange may reverse and seasonal or historic pollution of persistent substances in seawater may be partly returned to the atmosphere, like observed for a currently used pesticide, trifluralin in the North Sea (Theobald et al. 2013), as well as $\mathrm{HCH}$ in Arctic and Antarctic seas (Bidleman et al. 1995; Galbán-Malagón et al. 2013) and PCBs in the Mediterranean (Lammel et al. 2015).

More measurements are needed to establish temporal and even safe spatial trends. Air monitoring, at least at coastal stations, should be complemented by seawater monitoring in order to control atmospheric input of contaminants to the sea and the marine ecosystem.

Acknowledgments The PAS equipment was provided by Masaryk University, Research Centre for Toxic Compounds in the Environment, supported by the Czech Ministry of Education, Youth and Sports (LO1214 and LM2015051). The HVS used for the campaign of MayJune 2009 was provided by Helmholtz-Zentrum Geesthacht, Centre for Materials and Coastal Research, Geesthacht, Germany. C.M. was supported by the International Max Planck Research School for Maritime Affairs, Hamburg. We thank Jake Wilson, MPI, and an anonymous reviewer for comments on the manuscript. Open access funding provided by the Max Planck Society.

Open Access This article is distributed under the terms of the Creative Commons Attribution 4.0 International License (http:// creativecommons.org/licenses/by/4.0/), which permits unrestricted use, distribution, and reproduction in any medium, provided you give appropriate credit to the original author(s) and the source, provide a link to the Creative Commons license, and indicate if changes were made.

\section{References}

ARGE Elbe (2005) In: Bergemann M, Gaumert T, Stachel B (eds) Gewässergütebericht der Elbe 2004. Arbeitsgemeinschaft für die Reinhaltung der Elbe, Hamburg 19 pp

Atlas E, Giam CS (1981) Global transport of organic pollutants: ambient concentrations in the marine atmosphere. Science 211:163-165

Axelman J, Bandh C, Carman R, Jonsson P, Larsson H, Linder H, Näf C, Pettersen H (1995) Time-trend analysis of PAH and PCB sedimentation fluxes in the North Baltic-proper using different dating methods. Mar Freshw Res 46:137-144

Baart AC, Berdowski JJM, van Jaarsveld JA (1995) Calculation of atmospheric deposition of contaminants on the North Sea, Report \#R95/ 138, TNO, Delft, the Netherlands

Berrojalbiz N, Castro-Jiménez J, Mariani G, Wollgast J, Hanke G, Dachs J (2014) Atmospheric occurrence, transport and deposition of polychlorinated biphenyls and hexachlorobenzene in the Mediterranean and Black Seas. Atmos Chem Phys 14:8947-8959

Bethan B, Dannecker W, Gerwig H, Hühnerfuss H, Schulz M (2001) Seasonal dependence of the chiral composition of $\alpha-\mathrm{HCH}$ in coastal deposition at the North Sea. Chemosphere 44:591-597
Bidleman TF, McConnell LL (1995) A review of field experiments to determine air-water gas exchange of persistent organic pollutants. Sci Total Environ 159:101-117

Bidleman T, Jantunen LM, Falconer RL, Barrie LA, Fellin P (1995) Decline of hexachlorocyclohexane in the Arctic atmosphere and reversal of air sea gas exchange. Geophys Res Lett 22:219-222

BLMP (2005) Messprogramm Meeresumwelt: Zustandsbericht 1999 2002 für Nordsee und Ostsee. URL: http://www.blmp-online.de/

Bottenheim JW, Dastoor A, Gong SL, Higuchi K, Li YF (2004) Long range transport of air pollution to the Arctic. In: Stohl A (ed) Intercontinental transport of air pollution. Springer, BerlinHeidelberg, pp. 13-39

Brockmann UH, Haarich M, Rick HJ, Hühnerfuss H, Schmidt D, Kersten M, Steinhart H, Landgraf O, Aletsee L, Dürselen CD, Becker V (1994) Seasonal correlations between nutrients and contaminants. In: Sündermann J (ed) Circulation and contaminant fluxes in the North Sea. Springer, Berlin, pp. 485-520

Brubaker W, Hites R (1998) Hydroxyl radical reaction kinetics of gasphase $\alpha$ - and $\gamma$-hexachlorocyclohexane and hexachlorobenzene. Environ Sci Technol 32:766-769

Bruhn R, Kannan N, Petrick G, Schulz-Bull DE, Duinker JC (1999) Persistent chlorinated organic contaminants in harbour porpoises from the North Sea, the Baltic Sea and Arctic waters. Sci Total Environ 237/238:351-361

Bruhn R, Lakaschus S, McLachlan MS (2003) Air/sea gas exchange of polychlorinated biphenyls in the South Baltic Sea. Atmos Environ 37:3445-3454

BSH (2009) System Nordsee-Zustand 2005 im Kontext langzeitlicher Entwicklungen, Federal Maritime and Hydrographic Agency, Report No. 44, Hamburg, 270 pp

BSH (2013) System Nordsee-2006 \& 2007: Zustand und Entwicklungen, Federal Maritime and Hydrographic Agency Report No. 49, Hamburg, 193 pp

Cabrerizo A, Dachs J, Moeckel C, Ojeda MJ, Caballero G, Barcelo D, Jones KC (2011) Ubiquitous net volatilization of polycyclic aromatic hydrocarbons from soils and parameters influencing their soil-air partitioning. Environ Sci Technol 45:4740-4747

Denier van der Gon H, van het Bolscher M, Visschedijk A, Zandveld P (2007) Emissions of POPs and eight candidate POPs from UNECEEurope in 2000, 2010 and 2020 and the emission reduction resulting from the implementation of the UNECE POP protocol. Atmos Environ 41:9245-9261

Dittmann T, Becker PH, Bakker J, Bignert A, Nyberg E, Glória Pereira M, Pijanowska U, Sore RF, Stienen E, Toft GO, Marencic H (2012) Large-scale spatial pollution patterns around the North Sea indicated by coastal bird eggs with an EcoQC programme. Environ Sci Pollut Res 19:4060-4072

Draxler RR, Rolph GD (2003) HYSPLIT (HYbrid Single-Particle Lagrangian Integrated Trajectory). NOAA Air Resources Laboratory, Silver Spring, MD. Model access via URL http://www.arl.noaa.gov/ready/hysplit4.html

Dvorská A, Lammel G, Holoubek I (2009) Recent trends of persistent organic pollutants in air in Europe-air monitoring in combination with air mass trajectory statistics as a tool to study the effectivity of regional chemical policy. Atmos Environ 43:1280-1287

EMEP (2012) EMEP measurement data, European Monitoring and Evaluation Programme, URL: http://www.emep.int

Falandysz J, Kannan K, Tanabe S, Tatsukawa R (1994) Organochlorine pesticides and polychlorinated biphenyls in cod-liver oils: North Atlantic, Norwegian Sea, North Sea and Baltic Sea. Ambio 23:288-293

Faller J, Hühnerfuss H, König WA, Ludwig P (1991) Gas chromatographic separation of the enantiomers of marine organic pollutants: distribution of $\alpha-\mathrm{HCH}$ enantiomers in the North Sea. Mar Pollut Bull 22:82-86 
Galbán-Malagón C, Cabrerizo A, Caballero G, Dachs J (2013) Atmospheric occurrence and deposition of hexachlorobenzene and hexachlorocyclohexanes in the Southern Ocean and Antarctic Peninsula. Atmos Environ 80:41-49

Gerwig H (2000) Austausch und Transport luftgetragener schwerflüchtiger chlororganischer Verbindungen in Norddeutschland und über See (Angewandte Analytik Vol. 38), $\mathrm{PhD}$ thesis, University of Hamburg, Hamburg, Germany, $160 \mathrm{pp}$

Gioia R, Lohmann R, Dachs J, Temme C, Lakaschus S, Schulz-Bull D, Hand I, Jones KC (2008a) Polychlorinated biphenyls in air and water of the North Atlantic and Arctic Ocean. J Geophys Res 113: D19302

Gioia R, Nizzetto L, Lohmann R, Dachs J, Temme C, Jones KC (2008b) Polychlorinated biphenyls (PCBs) in air and seawater of the Atlantic Ocean: sources, trends and processes. Environ Sci Technol 42:1416-1422

Gouin T, Mackay D, Jones KC, Harner T, Meijer SN (2004) Evidence for the "grasshopper" effect and fractionation during long-range atmospheric transport of organic contaminants. Environ Pollut 128:139-148

Halsall CJ, Gevao B, Howsam M, Lee RGM, Ockenden WA, Jones KC (1999) Temperature dependence of PCBs in the UK atmosphere. Atmos Environ 33:541-552

Halse AK, Schlabach M, Eckhardt S, Sweetman A, Jones KC, Breivik K (2011) Spatial variability of POPs in European background air. Atmos Chem Phys 11:1549-1564

Halse AK, Schlabach M, Sweetman A, Jones KC, Breivik K (2012) Using passive air samplers to assess local sources versus long range atmospheric transport of POPs. J Environ Mon $14: 2580-2590$

He J, Balasubramanian R (2010) The exchange of SVOCs across the airsea interface in Singapore's coastal environment. Atmos. Phys Chem 10:1837-1852

Hoff RM, Brice KA, Halsall CJ (1998) Nonlinearities in the slopes of Clausius-Clapeyron plots for SVOCs. Environ Sci Technol 32: 1793-1798

Holoubek I, Klánová J, Jarkovský J, Kohoutek J (2007) Assessment of the central European trends in the background concentrations of persistent organic pollutants based on the results of the longterm integrated monitoring in Kosetice observatory, Czech Republic. Part I. Ambient air and wet deposition 19882005. J Environ Mon 9:557-563

Hühnerfuss H, Bester K, Landgraff O, Pohlmann T, Selke K (1997) Annual balances of hexachlorocyclohexanes, polychlorinated biphenyls and triazines in the German bight. Mar Pollut Bull 34:419-426

IHPA (2006) International HCH and Pesticides Association, the legacy of lindane $\mathrm{HCH}$ isomer production, $84 \mathrm{pp}$, online available: http://www.ihpa.info/resources/library/

Ilyina T, Lammel G, Pohlmann T (2008) Mass budgets and contribution of individual sources and sinks to the abundance of $\gamma-\mathrm{HCH}, \alpha-\mathrm{HCH}$ and PCB153 in the North Sea. Chemosphere $72: 1132-1137$

Iwata H, Tanabe S, Sakai N, Tatsukawa R (1993) Distribution of persistent organochlorines in the oceanic air and surface seawater and the role of ocean on their global transport and fate. Environ Sci Technol 27:1080-1098

Jantunen LM, Bidleman TF (1995) Reversal of the air-water gasexchange direction of hexachlorocyclohexanes in the Bering and Chukchi seas: 1993 vs. 1988. Environ Sci Technol 29: 1081-1089

Jaward FM, Farrar NJ, Harner T, Sweetman AJ, Jones KC (2004) Passive air sampling of PCBs, PBDEs and organochlorine pesticides across Europe. Environ Sci Technol 38:34-41

Klánová J, Kohoutek J, Hamplová L, Urbanová P, Holoubek I (2006) Üassive air sampling as a tool for longterm air pollution monitoring.
Part 1: Performance assessment for seasonal and spatial variations. Env Pollut 144:393-405

Lakaschus S, Weber K, Wania F, Schrems O (2002) The air-sea equilibrium and time trend of hexachlorocyclohexanes in the Atlantic Ocean between the Arctic and Antarctica. Environ Sci Technol 36:138-145

Lammel G, Klöpffer W, Semeena VS, Schmidt E, Leip A (2007) Multicompartmental fate of persistent substances: comparison of predictions from multi-media box models and a multicompartment chemistry-atmospheric transport model. Environ Sci Pollut Res 14:153-165

Lammel G, Klánová J, Kohoutek J, Prokeš R, Ries L, Stohl A (2009) Observation and origin of organochlorine pesticides, polychlorinated biphenyls and polycyclic aromatic hydrocarbons in the free troposphere over central Europe. Environ Pollut 157:3264-3271

Lammel G, Audy O, Besis A, Efstathiou C, Eleftheriadis K, Kohoutek J, Kukučka P, Mulder MD, Přibylová P, Prokeš R, Rusina TP, Samara C, Sofuoglu A, Sofuoglu SC, Taşdemir Y, Vassilatou V, Voutsa D, Vrana B (2015) Air and seawater pollution and air-sea gas exchange of persistent toxic substances in the Aegean Sea: spatial trends of PAHs, PCBs, OCPs, and PBDEs. Environ Sci Pollut Res 22:11301-11313

Lammel G, Meixner FX, Vrana B, Efstathiou C, Kohoutek J, Kukučka P, Mulder MD, Přibylová P, Prokeš R, Rusina TS, Song GZ, Tsapakis M (2016) Bi-directional air-sea exchange and accumulation of POPs (PAHs, PCBs, OCPs and PBDEs) in the nocturnal marine boundary layer. Atmos Chem Phys 16:6381-6393

Leip A, Lammel G (2004) Indicators for persistence and long-range transport potential as derived from multicompartment chemistrytransport modelling. Environ Pollut 128:205-221

Lin T, Li J, Xu Y, Liu X, Luo CL, Cheng HR, Chen YJ, Zhang G (2012) Organochlorine pesticides in seawater and the surrounding atmosphere of the marginal seas of China: spatial distribution, sources and air-water exchange. Sci Total Environ 435-436:244-252

Lipiatou E, Saliot A (1991) Hydrocarbon contamination of the Rhone delta and western Mediterranean. Mar Pollut Bull 22:297-304

Lohmann R, Muir DCG (2010) Global aquatic passive sampling (AQUA-GAPS): using passive samplers to monitor POPs in the waters of the world. Environ Sci Technol 44:860-864

Lohmann R, Breivik K, Dachs J, Muir D (2007) Global fate of POPs: current and future research directions. Environ Pollut 150:150-165

Lohmann R, Gioia R, Jones KC, Nizzetto L, Temme C, Xie Z, SchulzBull D, Hand I, Morgan E, Jantunen L (2009) Organochlorine pesticides and PAHs in the surface water and atmosphere of the North Atlantic and Arctic Ocean. Environ Sci Technol 43:5633-5639

Lohmann R, Klánová J, Kukučka P, Yonis S, Bollinger K (2012) PCBs and OCPs on a east-to-west transect: the importance of major currents and net volatilization for PCBs in the Atlantic Ocean. Environ Sci Technol 46:10471-10479

Mai C (2012) Atmospheric deposition of organic contaminants into the North Sea and the western Baltic Sea. PhD thesis. Department of Chemistry, University of Hamburg; URL: http://ediss.sub.unihamburg.de/volltexte/2012/5771

Mai C, Theobald N, Lammel G, Hühnerfuss H (2013) Spatial, seasonal and vertical distributions of currently-used pesticides in the marine boundary layer of the North Sea. Atmos Environ 75:92-102

Melymuk L, Robson M, Helm PA, Diamond ML (2011) Evaluation of passive air sampler calibrations: selection of sampling rates and implications for the measurement of persistent organic pollutants in air. Atmos Environ 45:1867-1875

Mulder MD, Heil A, Kukučka P, Klánová J, Kuta J, Prokeš R, Sprovieri F, Lammel G (2014) Air-sea exchange and gas-particle partitioning of polycyclic aromatic hydrocarbons in the Mediterranean. Atmos Chem Phys 14:8905-8915 
Mulder MD, Heil A, Kukučka P, Kuta J, Přibylová P, Prokeš R, Lammel G (2015) Long-range atmospheric transport of PAHs, PCBs, OCPs and PBDEs to the central and eastern Mediterranean 2010. Atmos Environ 111:51-59

O'Driscoll K, Mayer B, Ilyina T, Pohlmann T (2013) Modelling the cycling of persistent organic pollutants (POPs) in the North Sea system: fluxes, loading, seasonality, trends. J Mar Systems 111-112:69-82

Ockenden WA, Sweetman AJ, Prest HF, Steinnes E, Jones KC (1998) Toward an understanding of the global atmospheric distribution of persistent organic pollutants: the use of semipermeable membrane devices as time-integrated passive samplers. Environ Sci Technol 32:2795-2803

Paasivirta J, Sinkkonen S, Mikkelson P, Rantio T, Wania F (1999) Estimation of vapour pressures, solubilities and Henry law constants of selected POPs as functions of temperature. Chemosphere 39:811-832

Paterson S, Mackay D, Gladman A (1991) A fugacity model of chemical uptake by plants from soil and air. Chemosphere 23:539-565

Qiu X, Zhu T, Yao B, Hu J, Hu S (2005) Contribution of dicofol to the current DDT pollution in China. Environ Sci Technol 39:4385-4390

Schreitmüller J, Vigneron M, Bacher R, Ballschmiter K (1994) Pattern analysis of polychlorinated biphenyls (PCB) in marine air of the Atlantic Ocean. Intl J Environ Anal Chem 57:33-52

Semeena VS, Lammel G (2005) The significance of the grasshopper effect on the atmospheric distribution of persistent organic substances. Geophys Res Lett 32:L07804

Stemmler I, Lammel G (2009) Cycling of DDT in the global oceans 1950-2002: world ocean returns the pollutant. Geophys Res Lett 36:L24602

Stemmler I, Lammel G (2011) Air-sea exchange of semivolatile organic compounds-wind and/or sea surface temperature control of volatilisation studied using a coupled general circulation model. J Mar Systems 85:11-18

Theobald N, Lange W, Gählert W, Renner F (1995) Mass spectrometric investigations of water extracts of the river Elbe for the determination of potential inputs of pollutants into the North Sea. Fres J Anal Chem 353:50-56

Tuduri L, Harner T, Hung H (2006) Polyurethane foam (PUF) disks passive air samplers: wind effect on sampling rates. Environ Pollut 144:377-383

UNECE (1998) Convention on long-range transboundary air pollution, protocol on persistent organic pollutants, Arhus, Denmark

UNEP (2010) Stockholm Convention on Persistent Organic Pollutants (POPs) as amended in 2009, United Nations Environment Programme, URL: http://www.pops.int

Vijgen J, Abhilash PC, Li YF, Lal R, Forter M, Torres J, Singh N, Yunus M, Tian C, Schäffer A, Weber R (2010) Hexachlorocyclohexane $(\mathrm{HCH})$ as new Stockholm Convention POPs - a global perspective on the management of lindane and its waste isomers. Environ Sci Pollut Res 18:152-162

Wania F, Mackay D (1993) Global fractionation and cold condensation of low volatility organochlorine compounds in polar regions. Ambio 22:10-18

Yusà V, Coscollà C, Mellouki W, Pastor A, de la Guardia M (2009) Sampling and analysis of pesticides in ambient air. J Chromatogr A 1216:2972-2983

Zhong GC, Xie ZY, Möller A, Halsall C, Caba A, Sturm R, Tang JH, Zhang G, Ebinghaus R (2012) Currently used pesticides, hexachlorobenzene and hexachlorocylohexanes in the air and seawater of the German Bight (North Sea). Env Chem 4:405-415 